\title{
Green Mining Technology in Mining
}

\author{
Zhengkang Shi \\ China School of Resource and Environment Project, Wuhan University of Technology, Wuhan, \\ 430070, China
}

Keywords: Mining process, paste filling, mining operations.

\begin{abstract}
Coal is the most important resource in China, the number has been more than one-third of the world's coal total. Many problems caused by coal mining are very serious, such as the environmental issues, industrial accidents, resource destruction and other issues .So green mining technology in China's coal mining operations are very important. Aiming at this problem, this paper analyses the necessity of green mining and related technologies.
\end{abstract}

\section{Introduction}

Mining operations will inevitably cause damage to surface. Therefore along with mining we will inevitably lead to a series of ecological destruction and environmental pollution. Foreign mining has a long history, adequate funding and advanced technology, so they have improved the ecological protection awareness about mining, and invested a lot of money and technology. Due to lack of knowledge of mining, and mining environmental of our country is still underdeveloped. Especially with the gradual development of the mining industry, the environmental damage has intensified. Therefore adjustment mining concept, set up the establishment of green mining model is a trend about our mining.

Coal is an important energy.In recent years, China's coal mining technology has greatly improved. But in the coal mining process, there are still many outstanding issues.

\section{Basic Theory Green Mining Technology}

\subsection{Necessity of Green Mining}

(1)Serious safety problems in coal mining. China's coal production accounts for $1 / 3$ of the world, but the number of deaths accounted for $80 \%$ of the world's coal industry deaths. The following figure curve statistics of deaths and the percentage of tons of coal accident mortality:

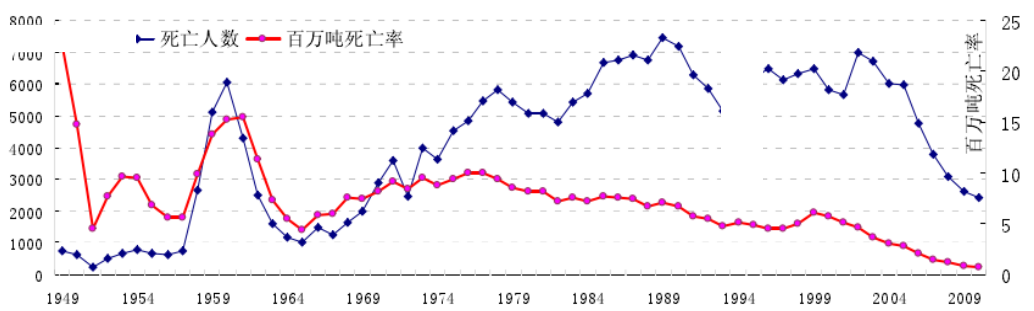

Fig.1: The statistics of megaton death-rate and mortality in China

The figure, the blue curve represents the number of deaths, the red curve represents the percentage.

By 2000-2007 China Coal production in the US coal industry can be seen in comparison with the security situation, China's coal production during the eight years is 1.67 times the US coal industry production; but the death toll is 187 times the United States; mortality US 113 times. In 2010, the Polish one million tons of coal mine death rate was 0.09, the South African mines one million tons mortality rate was 0.13 ; one million tons of Russian coal mine death rate was 0.34 .

(2)More serious environmental problems. Development and utilization of mineral resources with positive and negative values of two sides. Because of surface subsidence caused by mining area 
reached $400,000 \mathrm{~m}^{2}$, and the average rate of increase to $15,000 \mathrm{~m}^{2}$ per year. Surface deformation after mining can be seen in the picture below.

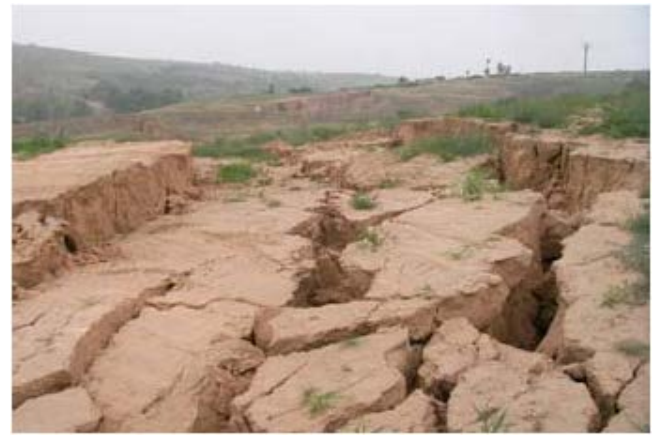

Fig.2: Photos of surface deformation after mining

(3)Coal resource recovery rate is significantly lower. Because coal resources have long occupied free coal-sided pursuit of high efficiency, resulting in a lot of mine waste of resources. The overall recovery rate of China's state-owned key coal mines only 30\%, the overall recovery rate of the state-owned local coal mines only $20 \%$, the overall recovery rate of only 10 percent of township coal mines. Li said that the national small coal resource recovery rate is only $15 \%$ even.

(4)The overall level of mechanization should be improved. 2008 national average of only $45 \%$ level of mechanization. State-owned key coal mining mechanization level of 83\%.Almost no mechanized mining township coal mines, there are about 2 million more than the coal miners are still engaged in manual. The following figure shows the trend of state-owned key coal mining mechanization. United States, Australia, Germany, Britain and other major coal-producing countries in the world, and its level of mechanization or close to $100 \%$.

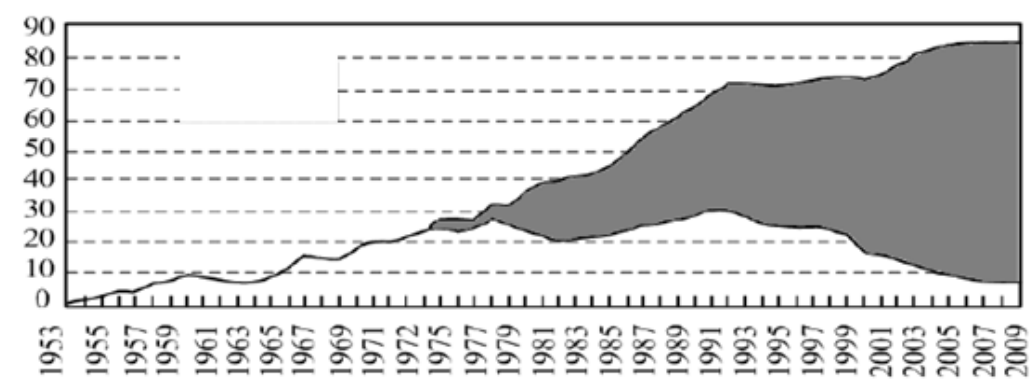

Fig.3: State-owned coal mining mechanization trend

\subsection{Connotation of Green Mining}

From the perspective of resources, coal, groundwater, coal bed methane (gas), land, coal and other mineral deposits in the vicinity of coal mining areas, should be the development and protection of objects of this mine. Green mining and green mining technology treat coal, gas, water and all kinds of resources that can be used. The basic starting point is to prevent or minimize the adverse effects of coal mining on the environment and other resources. The goal is to achieve the best economic and social benefits. According to land mines, groundwater, gas emissions and waste rock, green mining technologies include the following: water conservation, protection of land and buildings, gas drainage, etc. And corresponding three techniques are: Water conservation mining technology, filling mining technology, coal and gas extraction techniques, etc.

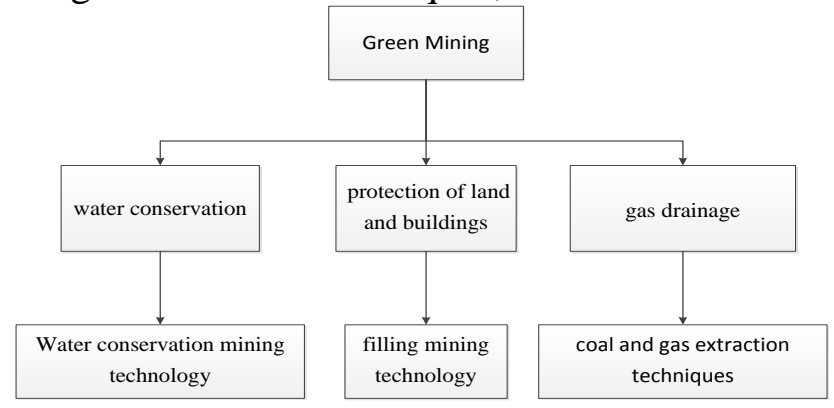

Fig. 4: Green Mining Technology 


\subsection{Green Mining Research Framework}

Green mining of coal is a huge system engineering. Just from the scientific and technological research, it is also very complex. Current progress is mainly reflected in the structure of the mined rock movement theory and percolation theory in theoretical research. In terms of technology development focus is reflected in the coal and gas extraction, mining and water conservation coal gangue back filling etc. Therefore, focusing on the existing framework is shown in Figure 2.

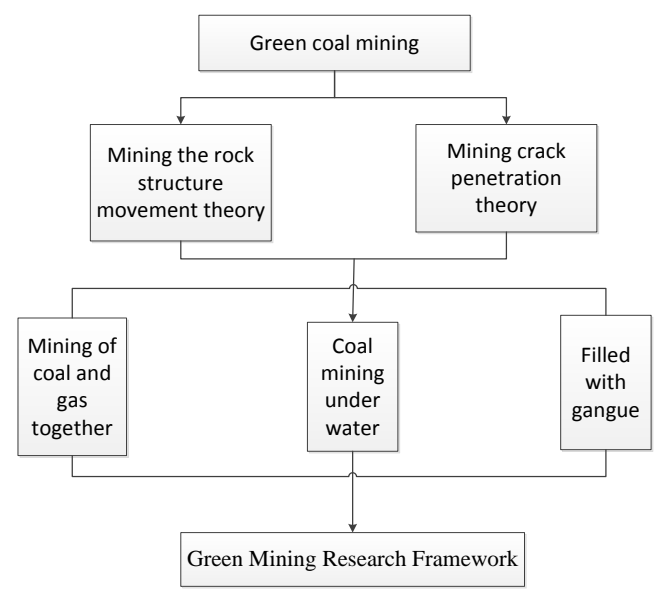

Fig .5: Basic system of the coal resource green mining

\section{Green Mining Technology}

Green mining technologies are emerging problem for coal mining. Its technical framework is shown as follows:

\subsection{Mining of Coal and Gas Together}

Coal seam gas drainage methods can be divided into two categories:

1) the former coal mining drainage;

2) relief during coal mining and mining after drainage.China's coal reservoirs generally have the characteristics such as high metamorphic grade, low permeability, low pressure and a small gas saturation .More than $70 \%$ of the coal seam permeability of less than $1 \times 10-3 \mu \mathrm{m} 2$. This situation for our country to carry out pre-extraction before coal seam gas mining is extremely unfavorable.

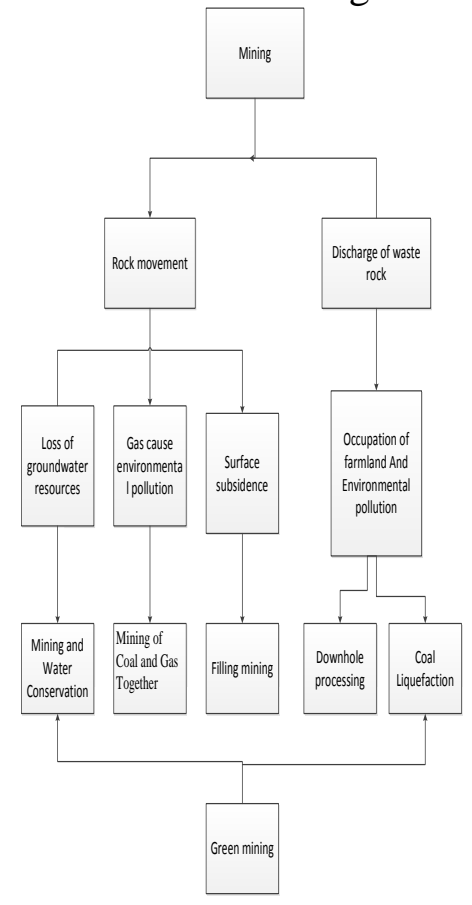

Fig .6: Green coal mining technology framework 
Practice shows that once rock movement caused by coal mining,even low permeability coal seam, it will also increase the number of times the permeability to several hundred times,To create the conditions for gas migration and drainage.Therefore, we should make full use of the process of mining rock movement increases the role of coal seam permeability, achieve mining of coal and gas together.

After years of scientific research, technological innovation and increased safety supervision and monitoring efforts, the technological level of China's coal mines, equipment and management level has made considerable progress Gas Treatment. Mining of coal and gas together has achieved remarkable results.

Figure 3 shows the Chinese coal mine gas drainage volume growth.Technology advances of China coal mine gas drainage,promote the coal mine production safety.Under conditions of rapid growth in coal production, coal mine deaths and millions of tons of mortality is declining.2007 state-owned key coal mines one million tons mortality down to 0.38 , and the gas explosion accident did not happen.

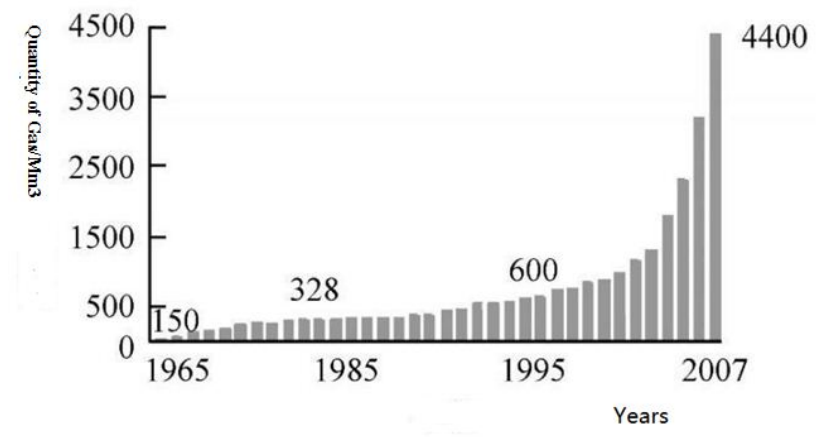

Fig .3 Increasing situation of gas drainage amount in coal mines of China

\subsection{Coal Mining Under Water}

To understand coal mining under water, we must understand the definition of WKS.Face to general water inrush will be several layers of rock barrier between the water,and all because of the hierarchical nature of the rock and live rock mining in different positions,so its performance is different.Water eventually need to penetrate that part of the rock is called WKS.The water there is two ways to break WKS, namely natural channel construction and mining road through cracks. Whichever route is opened, Water channel will be open.

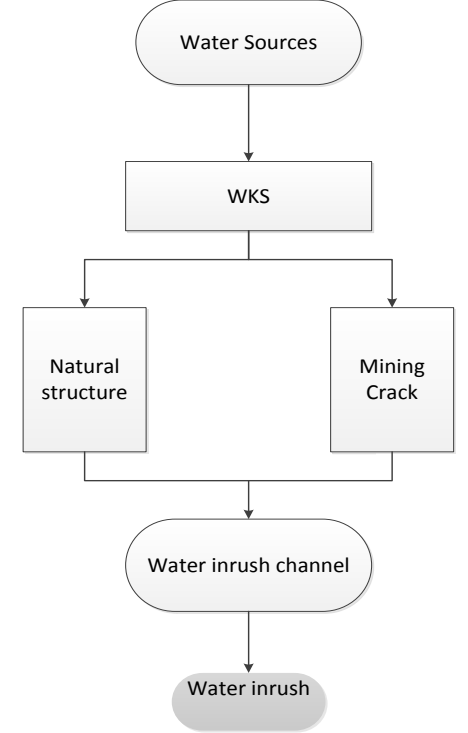

Fig .4 Sketch map of WKS

Visible water protection mining principles can be summarized as four steps: (1) determine the location of WKS;

(2) determine the stability and control of key impermeable layer structure;

(3) Identification and control of WKS seepage. Stability. (4) Control of the flow channel mutations. 


\subsection{Technology of Coal Replacement with Waste Rock}

We have developed the replacement of coal waste rock back filling set of technologies (including methods, processes and equipment).

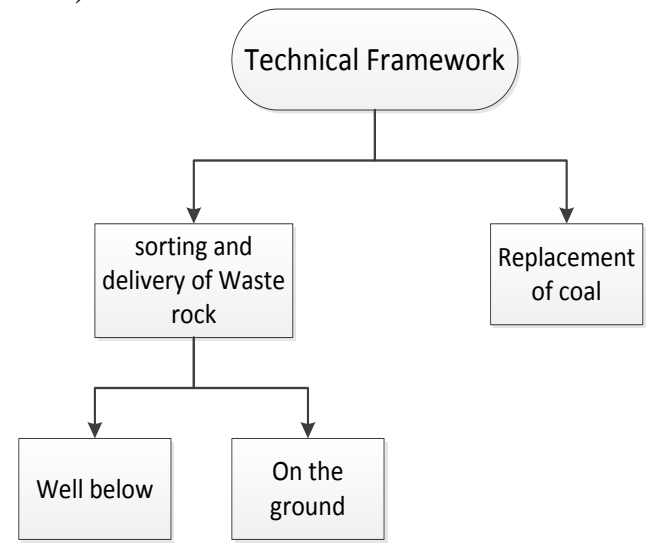

Fig .5 General technological framework of coal replacement with waste rock

The use of underground coal waste disposal goof filling mining method, not only can reduce solid waste coal, and can reduce the exploitation Subsidence disasters, improve mine resource recovery, is one of the key ways to achieve green coal mining.

\section{Conclusions}

Through the above discussion, the analysis shows that the green mining technology used in mining operations, has very important significance. In this paper, we give a detailed analysis of the application of green mining technology, it has the practical significance.

\section{Acknowledgements}

The research work was supported by National Natural Science Foundation of China under Grant No. 61065009 and Natural Science Foundation of Qinghai Provincial under Grant No. 2011-z-756.

\section{References}

[1] Benzaazoua M, Belem T, Bussiere B. Chemical factors that influence the performance of mine sulphidic paste back flll[J]. Cement and Concrete Research,2002,32(7):1133-1144.

[2] Deschamps T, Benzazoua M, Bussiere B, et ai. Micro structural and geo chemical evolution of paste tailings in surface disposal conditions[J]. Minerals Engineering,2008,21(4):341-353.

[3] Ouellet S, Bussiere B, Aubertin M, et al. Micro structural evolution of cemented paste back fill: Mercury intrusion porosimetry test results[J]. Cement and Concrete Research, 2007, 37(12): 1654-1665.

[4] M F, M B, E S. Mix proportioning of underground cemented paste back fill [J].International Journal of Tunnelling and Underground Construction, 2008,23:80-90.

[5] Yilmaz E, Kesimal A, Deveci H, et al. The factors affecting the performance of paste back fill; physical, chemical and mineralogical character ization: First Engineering 